\title{
Reuse of Eggshell Waste and Recycled Glass in the Fabrication Porous Glass-Ceramics
}

\author{
Dur Iffa Saparuddin ${ }^{1}$, Mohd Hafiz Mohd Zaid ${ }^{1,2, *(\mathbb{D}}$, Sidek Hj Ab Aziz ${ }^{1}$ and \\ Khamirul Amin Matori 1,2 \\ 1 Department of Physics, Faculty of Science, Universiti Putra Malaysia, UPM, Serdang, \\ Selangor 43400, Malaysia; iffadur@gmail.com (D.I.S.); sidek@upm.edu.my (S.H.A.A.); \\ khamirul@upm.edu.my (K.A.M.) \\ 2 Materials Synthesis and Characterization Laboratory, Institute of Advanced Technology, \\ Universiti Putra Malaysia, UPM, Serdang, Selangor 43400, Malaysia \\ * Correspondence: mhmzaid@upm.edu.my
}

Received: 18 June 2020; Accepted: 13 July 2020; Published: 5 August 2020

\begin{abstract}
This study was conducted to fabricate and characterize of glass-ceramic foam derived from soda-lime silica (SLS) glass waste and eggshell (ES) waste as a foaming agent by using empirical formula $[\mathrm{ES}] \times[\mathrm{SLS}]_{100-\mathrm{x}}$ where $\mathrm{x}=1 \mathrm{wt} \%, 3 \mathrm{wt} \%, 6 \mathrm{wt} \%, 9 \mathrm{wt} \%$. The samples undergo a heat-treatment process at temperature $800{ }^{\circ} \mathrm{C}$ with a heating rate of $10{ }^{\circ} \mathrm{C} / \mathrm{min}$. The properties of the samples were measured by average density measurement and linear expansion. The structural properties were studied by XRD, FESEM and FTIR concerning the different composition of the foaming agent while the mechanical properties were determined by compressive strength using UTM. The lowest density and compressive strength were achieved by $0.326 \mathrm{~g} / \mathrm{cm}^{3}$ and $0.04 \mathrm{MPa}$, respectively with the highest linear expansion at $77.33 \%$ by the addition of $3 \mathrm{wt} \%$ of ES. Moreover, the cristobalite phase $\left(\mathrm{SiO}_{2}\right)$ were identified after the heat treatment process. The production of foam glass-ceramics using SLS glass and ES can be applied to prepare different type of porosity that gives benefit to the environment and energy usage.
\end{abstract}

Keywords: compressive strength; crystal growth; foams; glass-ceramics; heat-treatment

\section{Introduction}

Globally, the increase of organic and inorganic waste caused by increasing human population growth as well as their lifestyle. Discarded waste such as waste glasses give a negative impact on the environment. For instance, the discarded cathode ray tube (CRT) panel from the electronic component and soda-lime-silica glass from the automotive industry are polluted with heavy metals [1,2]. To overcome this problem, both raw materials are utilized for making valuable materials such as manufacturing stoneware tiles, production of concrete blocks, fabrication of glass-ceramics materials, and the manufacture of foam glass-ceramics [3]. There is a wide sector application used to insulate the materials such as the construction industry, biochemistry industry, material engineering, military security, etc. [4].

Foam glass-ceramic is a thermal insulation material that has attracted much attention nowadays, function to retard heat flow due to its properties such as high thermal resistance. Generally, the foam glass is a solid bulk material, shaped by mixing the glass powder and foaming agent and then undergo a sintering process to form a porous structure. After the softening point temperature of the glass is reached, the solid phase turns to viscous liquid and facilitates the bubbles to grow inside the glass melt, hence foam formation has occurred when solidified the glass melt. The glass can provide an amorphous phase that led to better thermal insulation material's appearance. The pores were generated 
inside the body glass from the decomposition of the foaming agent either decomposition reaction or oxidation-reduction reaction to produce $\mathrm{CO}_{2}$ gas. There was a previous research use manganese oxide as an oxidizing agent meanwhile silica carbide as a carbon-containing [5]. For decomposition reaction, the raw materials are from commercial calcium carbonate, calcium carbonate from mollusk animal, eggshell and sodium carbonate [6-9].

The soda-lime-silicate (SLS) glass from bottle glass waste is reused in this research to fabricate foam glass-ceramics. SLS glass becomes great attention compared to conventional glass due to its characteristic in terms of optical and mechanical properties. Moreover, the use of SLS glass waste as an alternative way to get a source of $\mathrm{SiO}_{2}$ associated with glassy appearance [10]. Furthermore, the softening point of this glass $\sim 700^{\circ} \mathrm{C}$ [11]. Eggshell (ES) was used as a foaming agent of decomposition of calcium carbonate to carbon dioxide and calcium oxide. ES is obtained from urban waste (household, bakery, restaurant, etc.). There is an abundance of eggshells in landfills as Malaysian consume 20 million eggshells daily [12]. The waste of eggshells would give a negative impact on the environment because it can attract animals such as rats and mice to accumulate around eggshell wastes. Thus, reused of waste materials (SLS and ES) to wealth technology can be achieved in this study as well as the prevention of the greater bulk volume of wastes in landfill sites. Moreover, a few previous studies are using waste glass and ES as a source of calcium carbonate to fabricate foam glass-ceramics [7,13].

The feature of final product foam glass-ceramics depends on the composition of foaming agent, the particle size distribution of glass powder and foaming agent powder, sintering temperature and sintering duration. Decreasing in density as well as the thermal conductivity of foam glass-ceramic is influenced by the porosity. Increasing porosity is achieved by containing $3 \mathrm{wt} \%$ of eggshell and an excessive amount of ES contribute to the reduction in porosity [7]. Furthermore, the other previous study found that the apparent density of foam glass is $2.46 \mathrm{~g} / \mathrm{cm}^{3}$ at $5 \mathrm{wt} \%$ of ES associate with a fluorescent lamp as a glass matrix [14]. Previous work has revealed the crystal form in the glass at $10 \mathrm{wt} \%-18 \mathrm{wt} \%$ of the foaming agent while a low percentage of calcium carbonate shows an amorphous nature [6]. An increasing number of foaming agents leads to the induction crystallization process that causes the increase in viscosity of the system, hence reduce the ability of foam glass-ceramic to expand under internal gas pressure [15].

Ordinarily, the successful development of pores of foam glass-ceramics depends on the balance of the gas pressure generated and the viscosity of the system. The main objective of this work is to fabricate foam glass-ceramics derived from waste materials and to determine and study the effect of varying the content of ES to the physical, structural and mechanical properties of foam glass-ceramics.

\section{Materials and Methods}

The raw material used in this research were SLS glass waste bottle, ES as a foaming agent and polyvinyl alcohol (PVA) as a binder. The SLS glass waste was collected from the glass bottle of sauce (Brand: Life) from Pizza Hut IOI City Mall Putrajaya, Malaysia. The waste glass is usually contaminated from dirt and it must be washed before crushing. ES was collected from recycling containers located at Sri Serdang, Selangor, Malaysia restaurants which then rinsed with water and dried for $24 \mathrm{~h}$ in the dry oven before crushing. This process used to completely remove all dirt on the ES. Waste SLS glass and ES were crushed into the small glass cullet. The glass cullet then placed into milling jar with ceramic balls and was left at milling machine (US Stoneware Corp) for $24 \mathrm{~h}$ at the speed of $50 \mathrm{rpm}$ to get a fine glass powder. Then, the glass powder was filtered to obtain the powder with $45 \mu \mathrm{m}$ particle size using stainless steel sieve while the ES ground using pestle and mortar and sieve into $45 \mu \mathrm{m}$ size.

Figure 1 shows the flowchart of the sample preparation. First, SLS glass and ES powder were prepared with different weight percentages and weighed using a digital analytical balance. Both powders were put in a bottle according to the empirical formula and mix by using pestle and mortar. Then, the homogenous powder was pressed using a (Specac, Ltd., Orpington, UK) hydraulic pressing machine, with an applied load of $5 \mathrm{MPa}$ for 10-15 min and transformed into pellet form, 
13.10-mm diameter. The pellets placed into the alumina boat and went for the heat-treatment process. All samples were heat-treated at $800{ }^{\circ} \mathrm{C}$ for $1 \mathrm{~h}$ by using the electric furnace. After the heat treatment process, the pellets were grounded into $45 \mu \mathrm{m}$ in size and were sent to characterization.
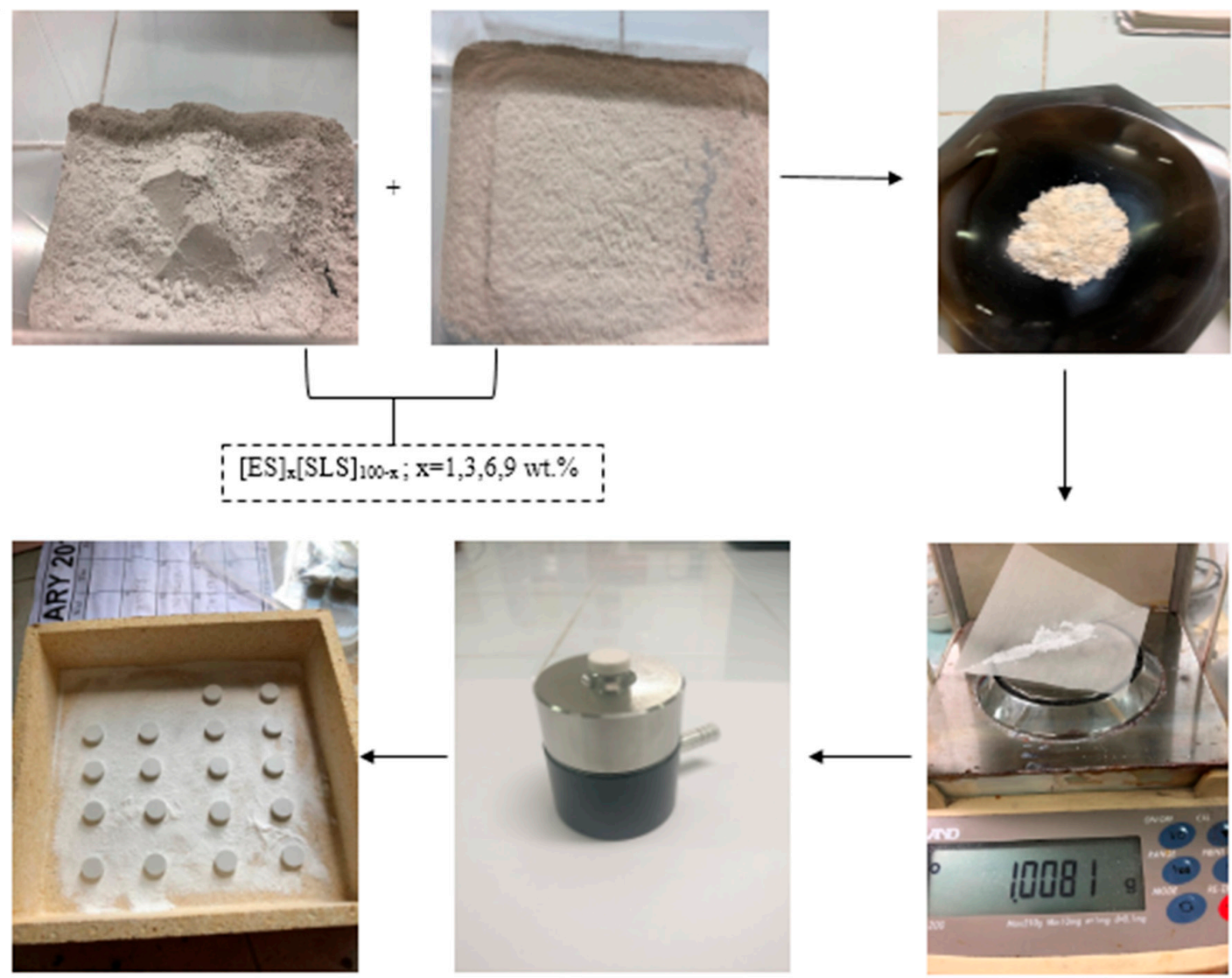

Figure 1. Schematic diagram of sample preparation.

Wavelength dispersive X-ray fluorescence (WD-XRF), (Bruker, S8 Tiger, Billerica, MA, USA) was used to analyze SLS and ES powder to identify chemical composition in both raw materials. Thermogravimetric Analyzer-Mettler Toledo (TGA/SDTA 851, Columbus, OH, USA) was used to determine the weight loss decomposition of ES with the temperature in the range of $27-1000{ }^{\circ} \mathrm{C}$. The finding results as shown in Table 1 and Figure 1 for XRF and TGA analysis, respectively.

Table 1. Chemical composition of SLS glass and ES.

\begin{tabular}{|c|c|c|c|c|c|c|}
\hline \multirow{2}{*}{$\begin{array}{c}\text { Raw } \\
\text { Materials }\end{array}$} & \multicolumn{6}{|c|}{ Constituents Oxides (wt \%) } \\
\hline & $\mathrm{SiO}_{2}$ & $\mathrm{CaO}$ & $\mathrm{Na}_{2} \mathrm{O}$ & $\mathrm{Al}_{2} \mathrm{O}_{3}$ & $\mathrm{MgO}$ & Others \\
\hline SLS & $70.5 \pm 0.1$ & $11.3 \pm 0.1$ & $12.5 \pm 0.1$ & $2.8 \pm 0.1$ & $2.0 \pm 0.1$ & $0.9 \pm 0.1$ \\
\hline ES & - & $54.2(96.8)^{\mathrm{a}} \pm 0.1$ & $0.4 \pm 0.1$ & - & $0.8 \pm 0.1$ & $2.0 \pm 0.1$ \\
\hline
\end{tabular}

The bulk density ( $\rho$ ) of the produced foam was measured by the Archimedes principle and the formula as shown in Equation (1).

$$
\rho_{b}=\frac{m}{v}=\left[\frac{W_{\text {air }}}{W_{\text {air }} W_{\text {water }}}\right] x \rho_{\text {water }}
$$

where $W_{\text {air }}$ is a weighted sample in air, $W_{\text {water }}$ is a weighted sample in water and $p$ is a density of water. 
The porosity was evaluated by comparing Archimedes analysis to true density using Brunauer-Emmett-Teller (BET) surface analysis. The ratio between density as follows:

$$
\varepsilon=\left(1-\frac{\rho_{b}}{\rho_{t}}\right) \times 100 \%
$$

where $p_{\mathrm{b}}$ is a bulk density, $p_{\mathrm{t}}$ is a true density.

The linear expansion (LE) of the produced material was measured by subtracting the diameter of the glass-ceramic pellet $\left(D_{\mathrm{f}}\right)$ after it was treated to the diameter of the glass-ceramic before treated $\left(D_{i}\right)$ using digital vernier caliper (Mitutoyo 500-196-20, Kanagawa, Japan). The percentage linear expansion of the treated foam glass-ceramic sample was determined using Equation (3).

$$
\% \text { of } \mathrm{LE}=\frac{(\mathrm{Df})-(\mathrm{Di})}{(\mathrm{Di})} \times 100 \%
$$

X-ray diffraction (XRD) was made from MPD X'PERT PRO PANalytical's (Philips, PW 3040/60, Almelo, The Netherlands and Malvern, UK) with $\mathrm{Cu}-\mathrm{K} \alpha$ radiation in the 20 range from $20^{\circ}$ to $80^{\circ}$. The software X'Pert Highscore plus software (PANalytical) was used to identify the crystal phase of foam glass-ceramics. The crystal phase content or crystallinity (\%) was evaluated by Origin 8 software based on a semicrystalline pattern of XRD. The formula of the crystal phase is

$$
C=\frac{A_{C}}{A_{A}+A_{C}} \times 100 \%
$$

where $C$ is the crystallinity or crystal content $(\%), A_{\mathrm{C}}$ is the diffraction peak area of the crystalline phase and $A_{\mathrm{A}}$ is the scattering peak area of the amorphous phase. The diffraction peak area of the crystalline phase was determined by the calculation of full width at half maximum (FHWM).

The sample undergoes FTIR analysis to identify the functional group of the sample from spectra recorded using FTIR Nicolet 6700 (Thermo Nicolet, Waltham, MA, USA) with 400-4000 nm of wavenumber. The morphology and microstructure of the foam glass-ceramics were analyzed by using FESEM Nova NanoSEM 230 (FEI, Hillsboro, OR, USA) and the size of pores diameter was evaluated by ImageJ software. The compressive strength was measured by using Universal Testing Machine (Instron 5566, Norwood, MA, USA) with a $10 \mathrm{kN}$ load of compression and crosshead speed at $0.5 \mathrm{~mm} / \mathrm{min}$. Before testing the strength, the inhomogeneous surface of foam glass-ceramics was refined by using a hacksaw and $\mathrm{SiC}$ abrasive paper then all the samples were cut to get a standardized size of $\sim 14.0 \mathrm{~mm} \times 8.0 \mathrm{~mm}$ of the disc. The compressive strength was determined by stress-strain curve analysis and recorded the average for each sample $(n=5)$.

\section{Results and Discussion}

\subsection{Composition of SLS Glass and ES}

Each of the precursor SLS glass and ES were chemically analyzed by using Wavelength Dispersive $X$-ray Fluorescence (WDXRF). The elemental analysis was measured in the oxide form as tabulated in Table 1. The chemical composition of the SLS glass waste in this research was similar to the SLS glass bottles. The ES used as a foaming agent mainly contained calcium carbonate $\left(\mathrm{CaCO}_{3}\right)$. From Table 1 , there was $95 \mathrm{wt} \%$ account for the element of $\mathrm{SiO}_{2}, \mathrm{CaO}$ and $\mathrm{Na}_{2} \mathrm{O}$ remarked the main constituents of the precursor glass. Meanwhile, the remaining percentage of other oxide elements were $\mathrm{Al}_{2} \mathrm{O}_{3}$ and $\mathrm{MgO}$ from the total composition of the precursor glasses.

ES powder undergoes TGA analysis to determine the weight loss decomposition of calcium carbonate, $\mathrm{CaCO}_{3}$ to carbon dioxide, $\mathrm{CO}_{2}$, and calcium oxide, $\mathrm{CaO}$ in the ratio 1:1. Figure 2 illustrates the TGA analysis of ES showed that the loss mass of calcium carbonate. The calcium carbonate starts to decompose about $6 \%$ of mass at $680{ }^{\circ} \mathrm{C}$ of temperature at the first stage and the second stage, the mass 
loss of calcium carbonate was intensified by $41 \%$ to carbon dioxide, $\mathrm{CO}_{2}$ and the other $53 \%$ was calcium oxide, $\mathrm{CaO}$ at $810^{\circ} \mathrm{C}$ of temperature. The finding percentage mass loss of calcium oxide was agreed with XRF analysis as shown in Table 1 . After $810^{\circ} \mathrm{C}$ of temperature, there was no more decompose of calcium carbonate. The weight loss of carbonate relative to the temperature in this research is similar to the previous study which states that decompose temperature of eggshell in the range of $700-850{ }^{\circ} \mathrm{C}$ of temperature [14]. Therefore, $800{ }^{\circ} \mathrm{C}$ of temperature was selected as the sintering temperature in this research.

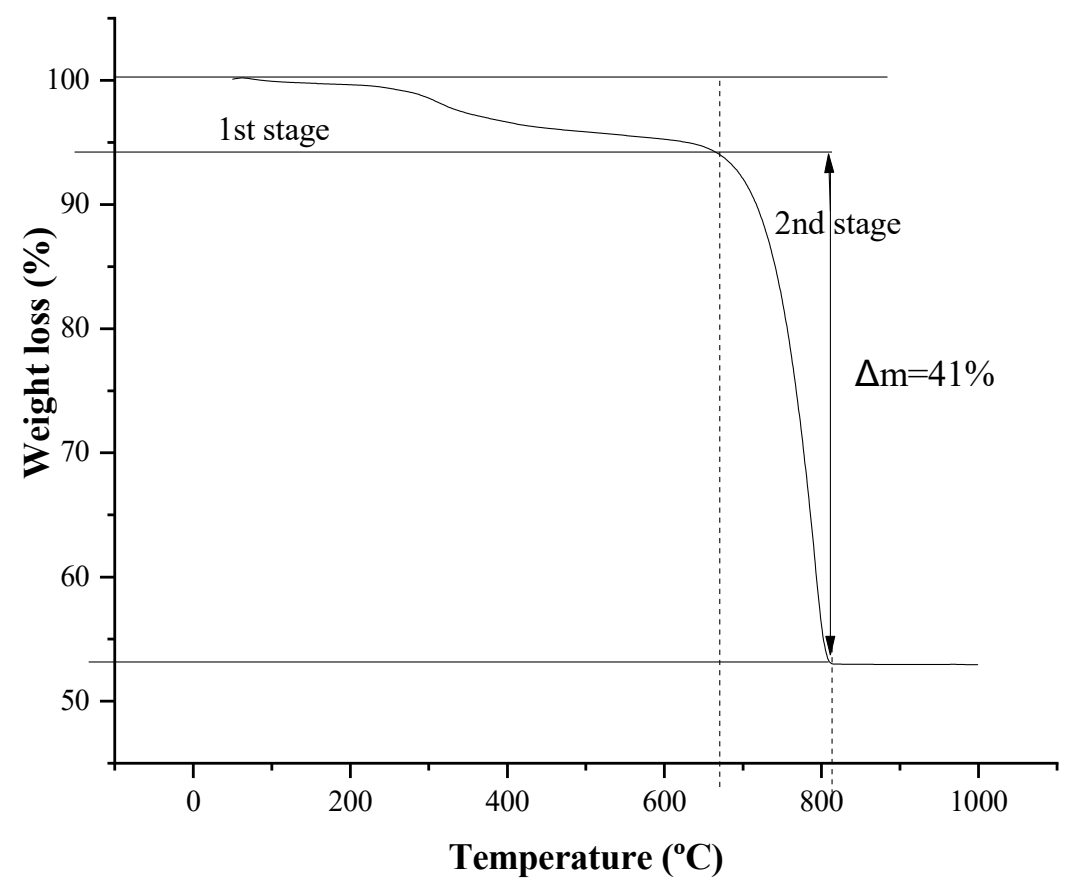

Figure 2. Weight loss of calcium carbonate as a function of temperature.

\subsection{Physical and Mechanical Analysis}

Bulk density of the foam glass-ceramics for 1, 3, $6 \mathrm{wt} \%$ and $9 \mathrm{wt} \%$ ES were 1.215, 0.326, 0.421 and $0.822 \mathrm{~g} / \mathrm{cm}^{3}$, respectively. The trend for the bulk density was similar to the compressive strength value. Figure 3 indicates the trend of bulk density-porosity of foam glass-ceramics at different content of ES. Porosity is calculated with the constant value of $\rho_{\text {powder }}=2.5 \mathrm{~g} / \mathrm{cm}^{3}$. The porosity was indirectly proportional to the bulk density. Figure 2 shows the minimum density was achieved from $3 \mathrm{wt} \% \mathrm{ES}$ with $87 \%$ of porosity. Meanwhile, the maximum density was $1.215 \mathrm{~g} / \mathrm{cm}^{3}$ from $1 \mathrm{wt} \%$ ES with the lowest porosity of $51.4 \%$. The value is in the range of commercial foam glass, which is $0.1-1.2 \mathrm{~g} / \mathrm{cm}^{3}$ [15]. Linear expansion of a sample is the changing of size and dimension of the sample thus higher of linear expansion percentage contributes to the reducing volume of the sample. The linear expansion curve as shown in Figure 4, shows that the linear expansion value have an insignificant difference between $1 \mathrm{wt} \%$ and $9 \mathrm{wt} \% \mathrm{ES}$. The maximum linear expansion from $3 \mathrm{wt} \% \mathrm{ES}$ with the value was $77.33 \%$ meanwhile the minimum linear expansion was $59.62 \%$ from $9 \mathrm{wt} \%$ ES. Therefore, decreasing in a volume of foam glass-ceramics would give to the high density. The difference value of density caused by the difference content of ES. The higher content of ES would have an increasing amount of crystallite hence give increasing the viscosity of the system [14]. 


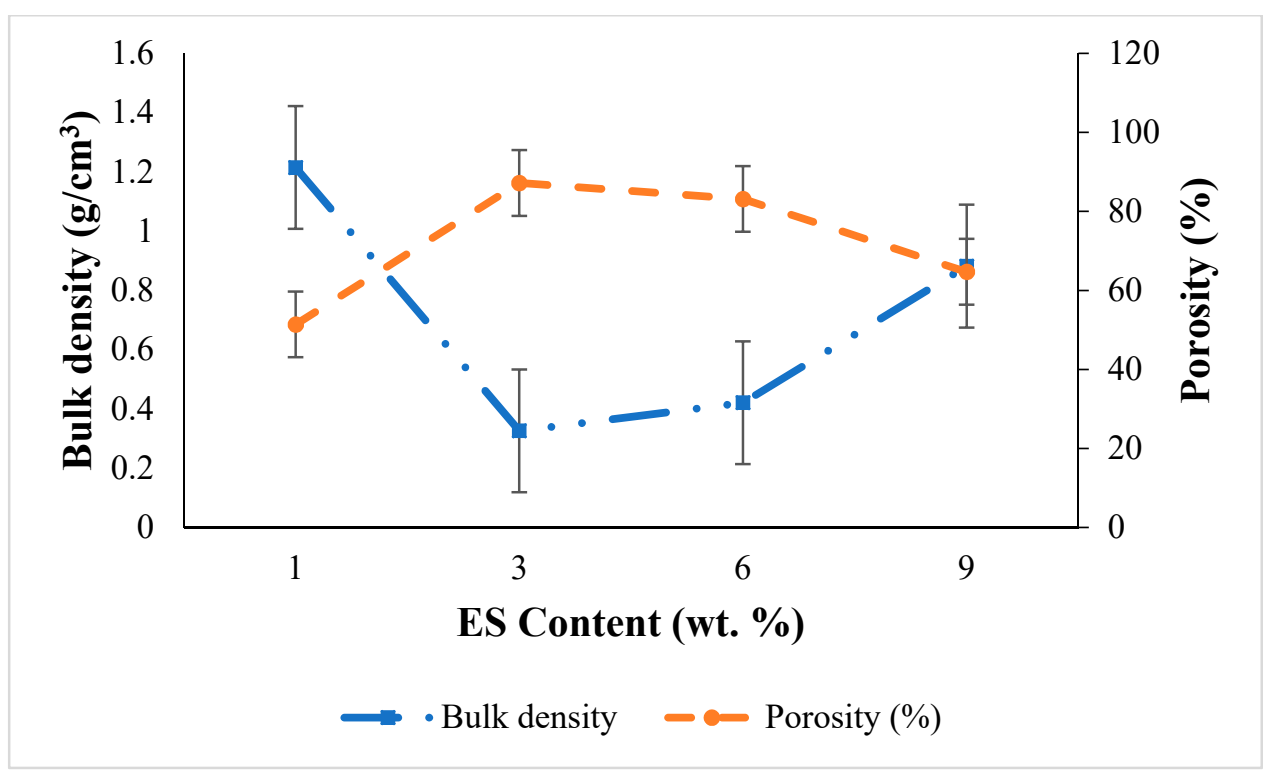

Figure 3. Bulk density-porosity relative to the content of eggshell (ES).

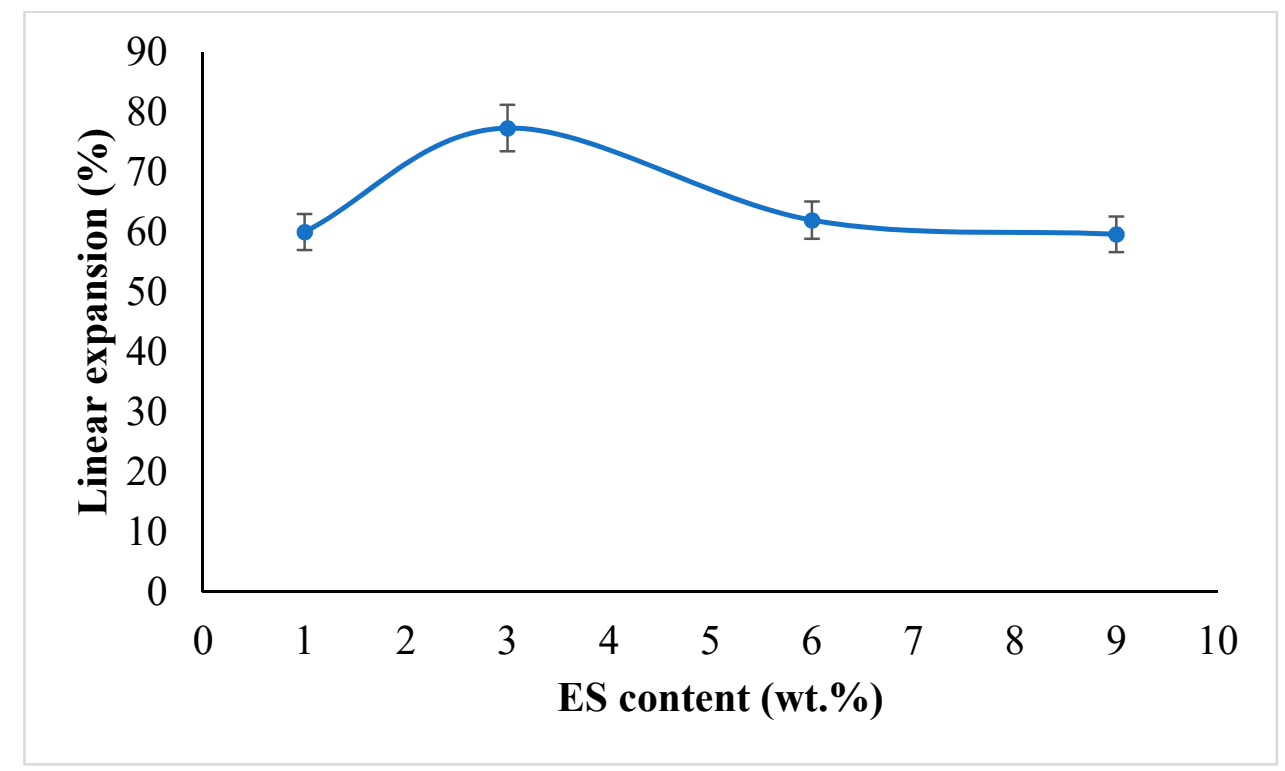

Figure 4. Linear expansion curve at different content of ES.

The compressive strength of foam glass-ceramics was determined by stress-strain curve analysis as shown in Figure 5. From the stress-strain curve, the ultimate strength point was determined beyond before the cracking of the samples [16,17]. The curve for $3 \mathrm{wt} \%$ of ES was slightly invisible because of the minimum value of the strength of $0.04 \mathrm{MPa}$. The maximum compressive strength from $9 \mathrm{wt} \%$ ES which was $0.81 \mathrm{MPa}$. Figure 6 shows the relation of porosity-compressive strength respective to the different content of the foaming agent. From the graph, the compressive strength was decreased drastically from $1 \mathrm{wt} \%$ to $3 \mathrm{wt} \%$ ES and increase slightly as adding more ES content to the $6 \mathrm{wt} \%$ and $9 \mathrm{wt} \%$. The lowest strength from $3 \mathrm{wt} \%$ ES which was $0.04 \mathrm{MPa}$ with the highest porosity. This is indicating that low in strength caused by high in porosity attributed to the expansion of the samples. Meanwhile, there was a significant difference in compressive strength between $1 \mathrm{wt} \%$ and $3 \mathrm{wt} \% \mathrm{ES}$. There may be an insufficient amount of $\mathrm{CO}_{2}$ gas generated in from $1 \mathrm{wt} \% \mathrm{ES}$. In fact, the high content of $\mathrm{SiO}_{2}$ can cause a lack of liquid phase thus no expansion [18]. 


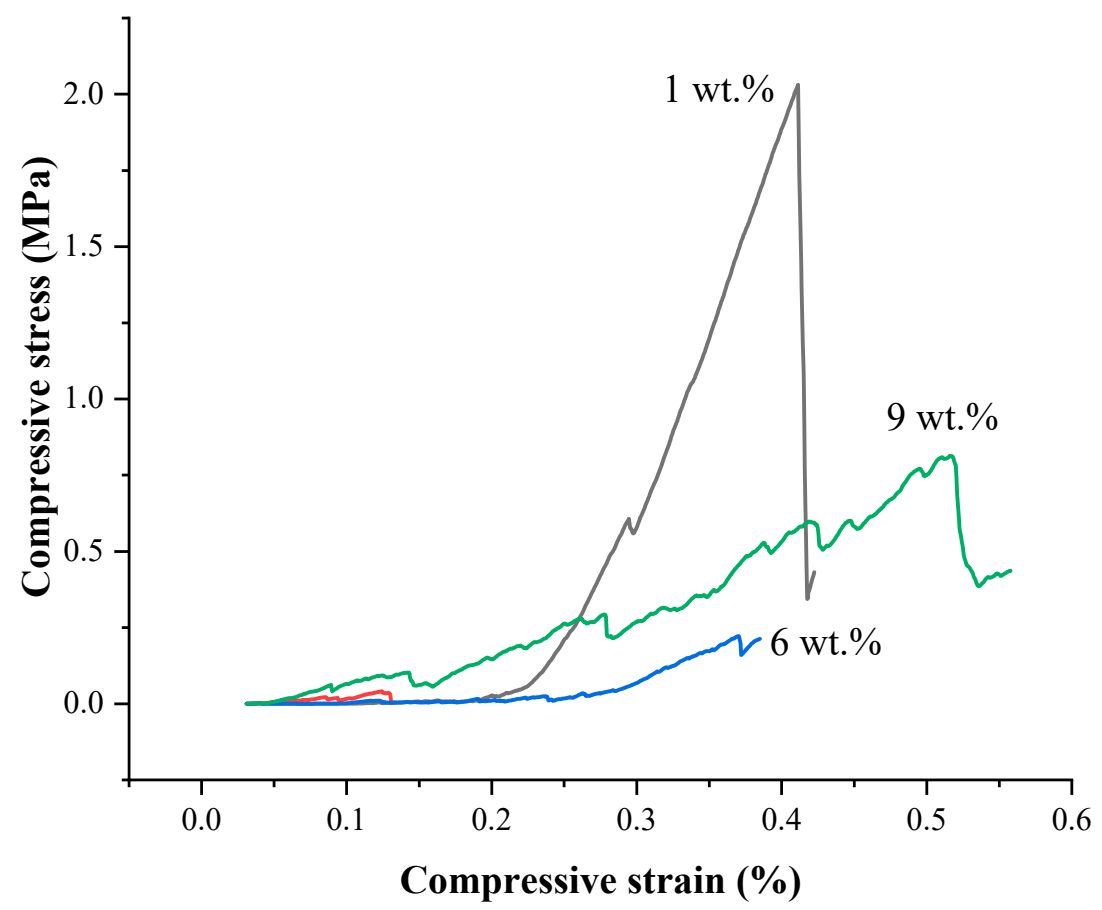

Figure 5. Stress-strain curve relative to the content of ES.

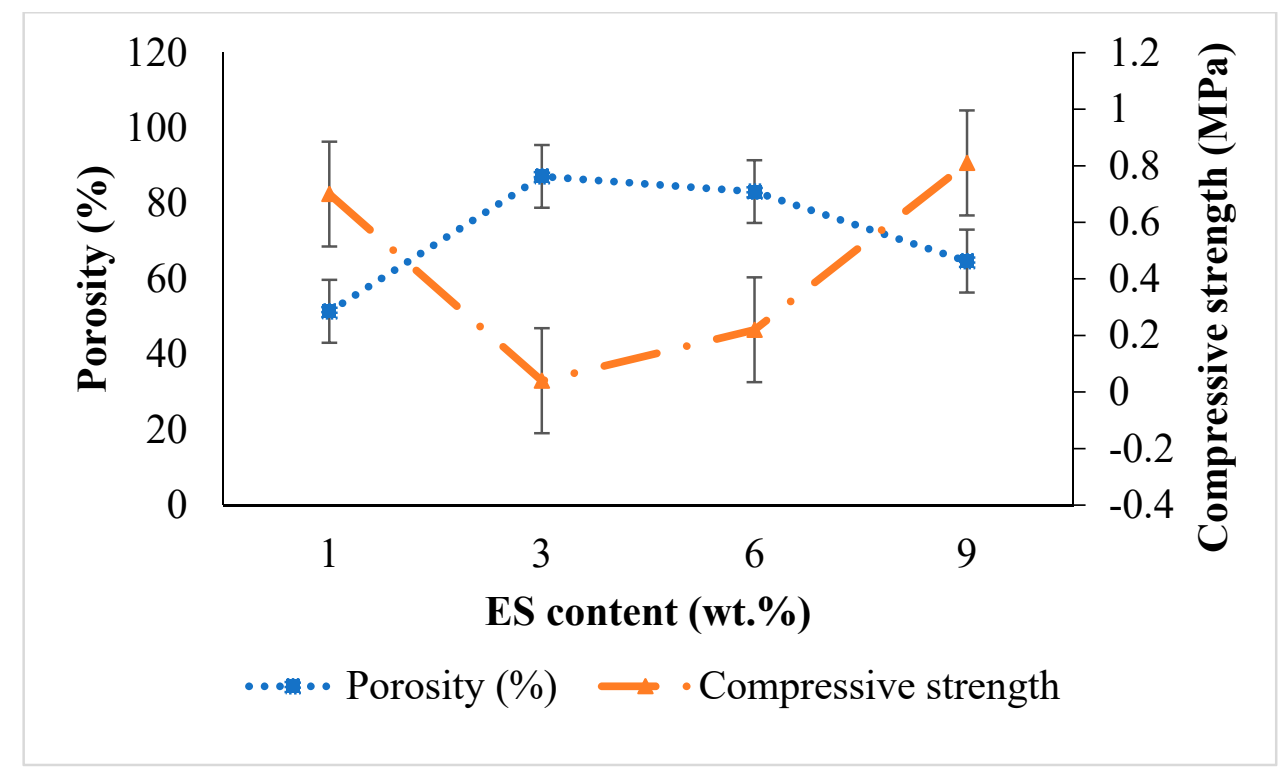

Figure 6. Linear expansion-compressive strength relative to the content of ES.

\subsection{Structural Analysis}

As discussed on the physical properties of foam glass-ceramics earlier, the finding can be verified through microstructure analysis as shown in Figure 7. Figure 7 shows that the pore distribution closed pores of foam glass-ceramics at different content of ES. Based on Figure 7a, it shows that the small pores appeared with homogeneously distributed. The average size of the pore diameter was $682 \mu \mathrm{m}$. Increasing the ES content to the $3 \mathrm{wt} \%$ gives a significant difference in the pore size as shown in Figure $7 \mathrm{~b}$. Therefore, the diameter of the pore distributed from $3 \mathrm{wt} \% \mathrm{ES}$ was in the range of $870-1500 \mu \mathrm{m}$. The pores revealed from $6 \mathrm{wt} \%$ ES as shown in Figure 7c was insignificant different from pore distribution between $3 \mathrm{wt} \%$ ES. However, the microstructure shows that there was an inhomogeneous pore distribution; indicate small pores which the size of diameter in the range of $250-350 \mu \mathrm{m}$ while for large pores in the range of $861-1200 \mu \mathrm{m}$ of diameter. This phenomenon occurs 
due to the high internal pressure inside the pores. Indeed, the high content of the foaming agent would increase the gas pressure and outweighs the strength of pore walls, thus making open pores in the surface [19]. Moreover, the previous research by using banana leaves as a foaming agent stated that the samples contain high banana leaves could cause the release of gases as a result break of the pore's wall and coalescence of pores occur [20]. Meanwhile, as an increasing amount of ES to $9 \mathrm{wt} \%$, it can see the decrease in pores, $508-700 \mu \mathrm{m}$ of diameter as shown in Figure $7 \mathrm{~d}$ due to the high viscosity of the system. The changing of viscosity influenced by the crystallization process inside the glass melt [21]. The previous research study by using coal fly ash and $\mathrm{CaCO}_{3}$ revealed that pores are homogenized sized obtained with $6 \%$ of calcium carbonate [22].
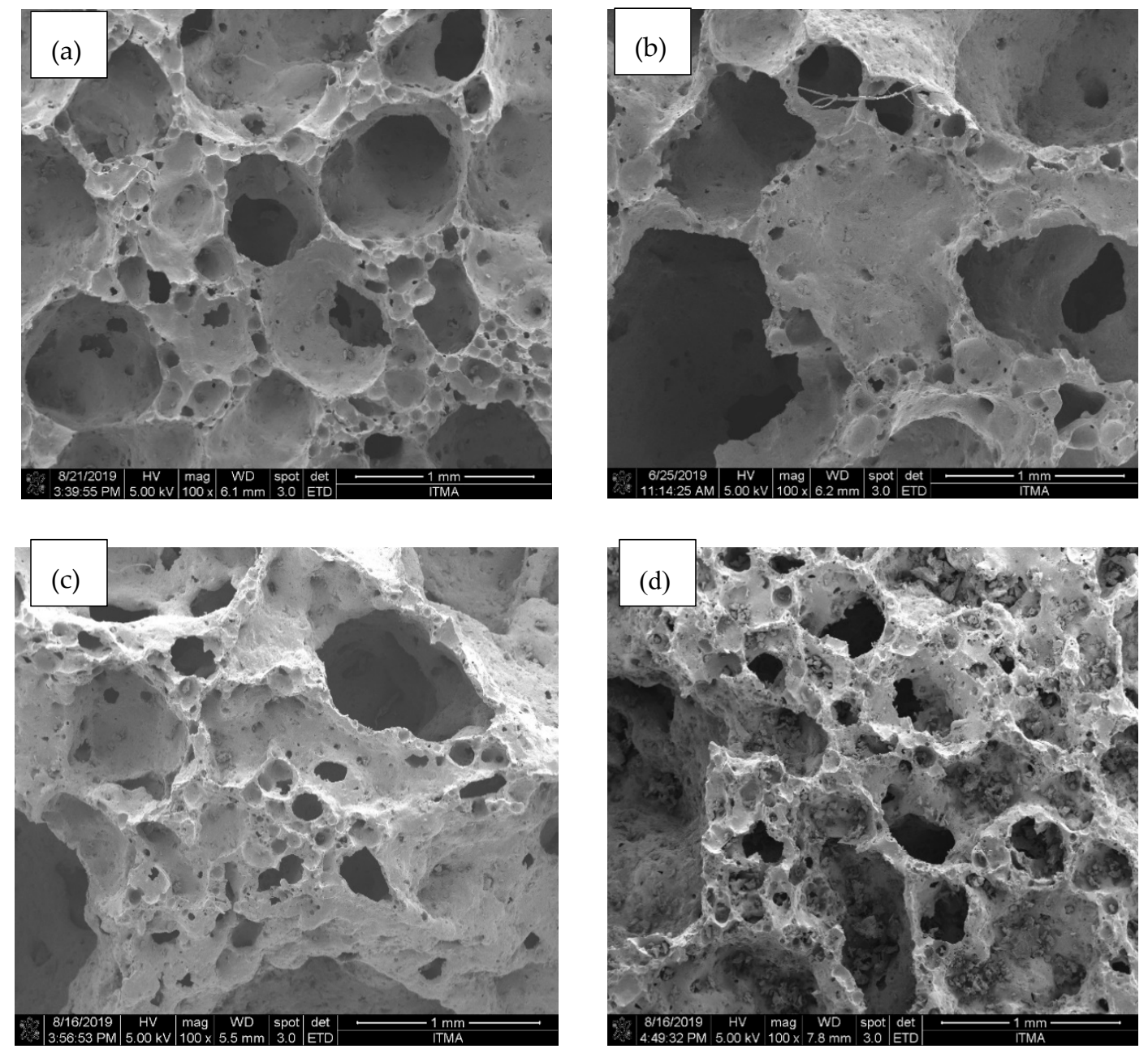

Figure 7. Microstructure of foam glass-ceramics. (a) $1 \mathrm{wt} \%$; (b) $3 \mathrm{wt} \%$; (c) $6 \mathrm{wt} \%$; (d) $9 \mathrm{wt} \%$ ES.

Figure 8 shows the XRD pattern of $1 \mathrm{wt} \%, 3 \mathrm{wt} \%, 6 \mathrm{wt} \%$ and $9 \mathrm{wt} \% \mathrm{ES}$ at $800{ }^{\circ} \mathrm{C}$ of temperature. There was a sharp peak of cristobalite $\left(\mathrm{SiO}_{2}, 96-900-8228\right)$ at $1 \mathrm{wt} \% \mathrm{ES}$ because of the high content of $\mathrm{SiO}_{2}$ while a little growth of wollastonite $\left(\mathrm{CaSiO}_{3}, 96-900-5778\right)$ with $33.26 \%$ of crystallinity. Percent of the crystallinity of the semicrystalline phase was determined and evaluated. The amorphous region exists as a broad hump in the range of $21-35^{\circ}$ of $2 \theta$ meanwhile the crystalline phase was formed underlying the amorphous phase. The observed peak of the crystalline phase was compared with the reference pattern by the Crystallography Open Database (COD). Therefore, the finding peak in this research was cristobalite $\left(\mathrm{SiO}_{2}, 96-900-8228\right)$ located at $\sim 22^{\circ}$ of $2 \theta$ and wollastonite $\left(\mathrm{CaSiO}_{3}\right.$, 96-900-5778) located $27^{\circ}, 29^{\circ}, 30^{\circ}$ and $32^{\circ}$ of $2 \theta$. As increasing ES content to $3 \mathrm{wt} \%, 6 \mathrm{wt} \%$ and $9 \mathrm{wt} \%$, the crystallinity was $37.89 \%, 38.19 \%$ and $66.80 \%$, respectively. The high crystal content from $9 \mathrm{wt} \%$, which contributes to the high viscosity of glass melt. Consequently, it would give an 
impact on the physical properties of foam-glass ceramics due to the insufficient foaming in glass melt [21]. Hence, $3 \mathrm{wt} \%$ of ES revealed an optimum phase of cristobalite and wollastonite. For $1 \mathrm{wt} \%$ of ES, there was an early stage of crystallization where the highest growth of cristobalite $\left(\mathrm{SiO}_{2}\right.$, 96-900-8228) because of the high content of $\mathrm{SiO}_{2}$ and small peak intensity of wollastonite $\left(\mathrm{CaSiO}_{3}\right.$, 96-900-5778). Meanwhile, the intensity of cristobalite $\left(\mathrm{SiO}_{2}, 96-900-8228\right)$ slightly decreased and the peak of wollastonite $\left(\mathrm{CaSiO}_{3}, 96-900-5778\right)$ has appeared for the $3 \mathrm{wt} \%$ of ES. As increasing the amount of ES to $6 \mathrm{wt} \%$, the intensity of cristobalite was decreased associates to promote the growth of wollastonite $\left(\mathrm{CaSiO}_{3}, 96-900-5778\right)$. Similarly, at $9 \mathrm{wt} \% \mathrm{ES}$ revealed the growth of wollastonite $\left(\mathrm{CaSiO}_{3}\right.$, 96-900-5778) due to the remaining calcium oxide would be induced to the crystallization process. The high content of ES would promote crystallization which led to the high viscosity of the system thus limiting the ability of foam expansion $[14,21]$. The previous study by using clamshell as a foaming agent states that an increasing amount of clamshell would increase the degree of crystallization because the presence of calcium oxide in the samples has reached the solubility limit [6].

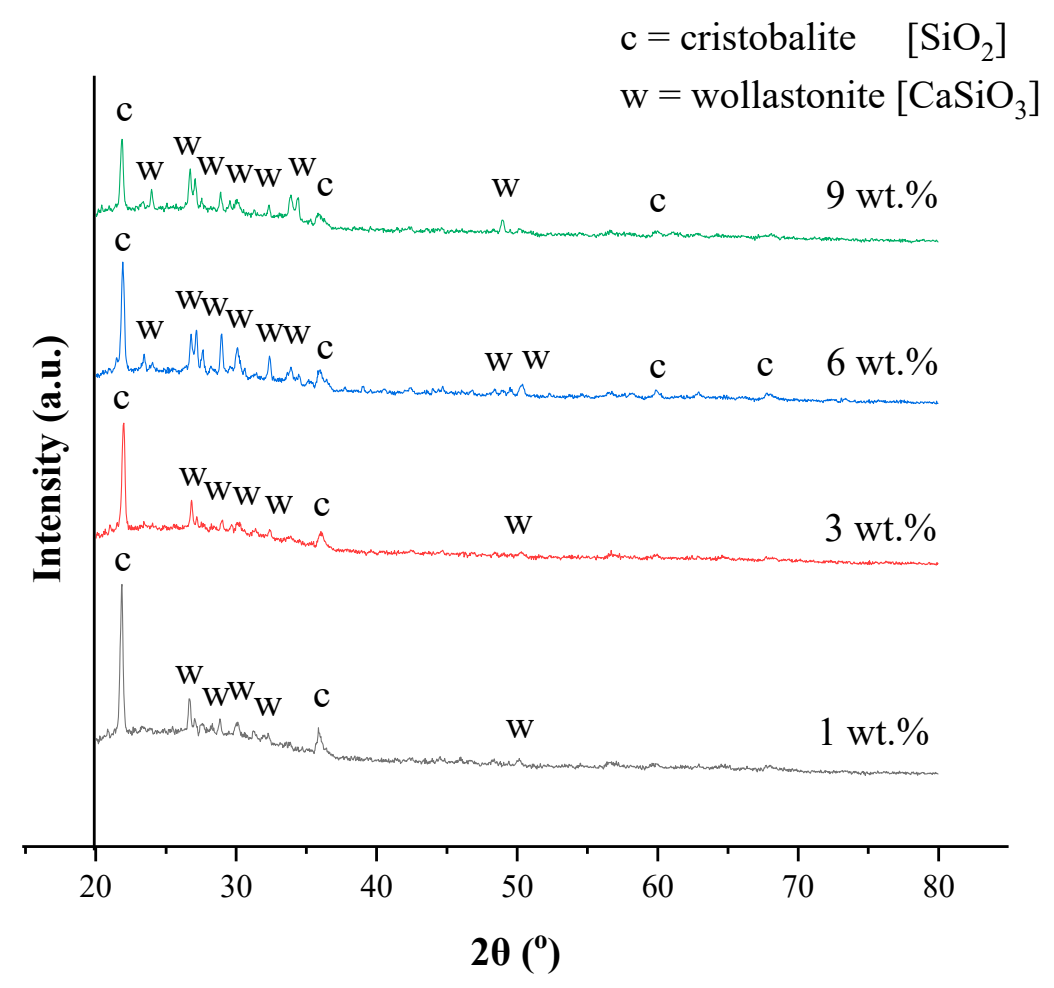

Figure 8. XRD pattern at different content of ES with a reference peak of wollastonite $\left(\mathrm{CaSiO}_{3}\right.$, 96-900-5778).

Figure 9 shows that FTIR analysis at different content of ES to identify a functional group in an element as well as to assist the finding of XRD results. The low-frequency bands in the range $400-600 \mathrm{~cm}^{-1}$ of wavenumber originate from $\mathrm{Ca}-\mathrm{O}$ stretching and bending modes of $\mathrm{O}-\mathrm{Si}-\mathrm{O}$ [23]. Homogeneous silica is formed only by $\mathrm{Si}-\mathrm{O}-\mathrm{Si}$ bonds meanwhile heterogeneous silica atom is formed with different bonds other than silica. An asymmetric stretch network of silica is increased with the presence of heteroatom meanwhile symmetric of silica bonding is decreased. The band of $\mathrm{Ca}-\mathrm{O}$ was slight intense for $6 \mathrm{wt} \%$ and $9 \mathrm{wt} \%$ ES at $600 \mathrm{~cm}^{-1}$ of wavenumber compared to the $1 \mathrm{wt} \%$ and $3 \mathrm{wt} \% \mathrm{ES}$ due to the growth of $\mathrm{CaSiO}_{3}$ as found in XRD analysis meanwhile, the band of symmetric, vs. $\mathrm{SiO}_{2}$ at $\sim 750 \mathrm{~cm}^{-1}$ of wavenumber were decreased due to the bonding of heteroatom, $\mathrm{Ca}-\mathrm{Si}-\mathrm{O}$. The wavenumber of asymmetric, $\mathrm{va}_{\mathrm{a}}$ of $\mathrm{Si}-\mathrm{O}$ was located in the range of $800-1250 \mathrm{~cm}^{-1}$ indicate the main strong peak with the rich in phase because of the presence of silica in SLS glass powder. Moreover, the wider band at $950 \mathrm{~cm}^{-1}$ of wavenumber was caused by the superposition of the absorption peak related to the stretching vibration of bridging and nonbridging $\mathrm{Si}-\mathrm{O}$ chemical bonds [24]. Consequently, 
it promotes the migration of the ions, $\mathrm{Ca}$, and change the structural silica network. The band at $1440-1450 \mathrm{~cm}^{-1}$ of wavenumber assigned that band of carbonate, $\mathrm{C}-\mathrm{O}$ group. As increasing the content of ES to $9 \mathrm{wt} \%$ of ES the band indicates strongly intense at $1450 \mathrm{~cm}^{-1}$ of wavenumber compared to the band at $1 \mathrm{wt} \%-6 \mathrm{wt} \%$ of ES. This is because of the partial decomposition of calcium carbonate from ES to carbon dioxide at $810^{\circ} \mathrm{C}$ of temperature as discussed from TGA analysis. There is a little amount of calcium carbonate at high content of ES since the other previous study stated that calcium carbonate is undetectable above $824{ }^{\circ} \mathrm{C}$ of temperature [25]. Lastly, there was a slight peak located in the range of 2050-2250 $\mathrm{cm}^{-1}$ represent the ambient of carbon dioxide, $\mathrm{CO}_{2}$ the main element in this research [26].

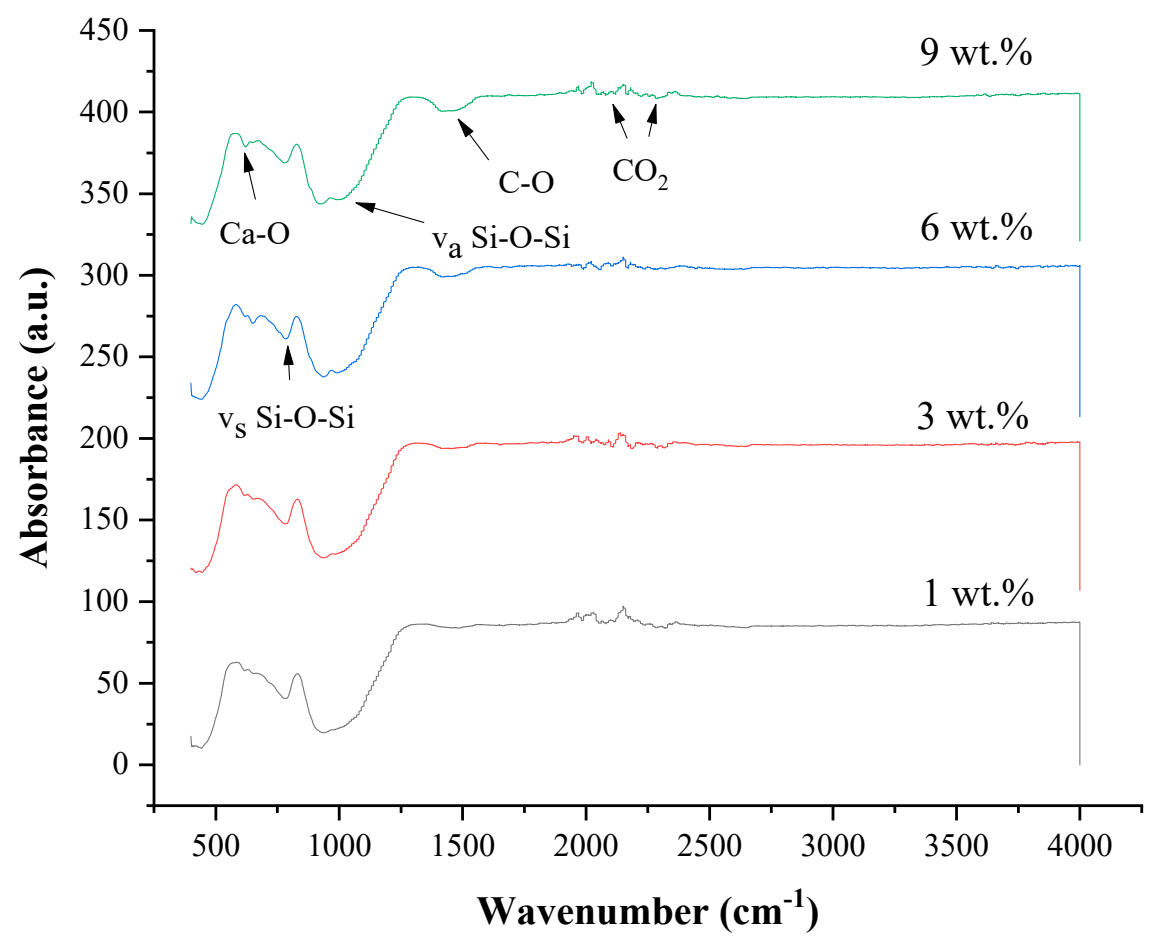

Figure 9. FTIR band at different content ES.

\section{Conclusions}

In present work, foam glass-ceramics with low in bulk density and relatively high compressive strength can be produced from a mixture of waste SLS glass and ES as a foaming agent by heat treatment process at $800{ }^{\circ} \mathrm{C}$ of temperature for $60 \mathrm{~min}$. The content of ES gives an effect on bulk density, porosity, linear expansion and compressive strength. Foam glass-ceramics that have low in bulk density $\left(0.421 \mathrm{~g} / \mathrm{cm}^{3}\right)$ and high compressive strength $(0.22 \mathrm{MPa})$ from $6 \mathrm{wt} \% \mathrm{ES}$. In terms of structural properties, the increase in the content of ES led to the smaller number of pores caused by high densification of the glass matrix. Moreover, the highest crystal phase content such as wollastonite would hinder the foam formation and give an impact to the properties of foam glass-ceramics that influenced by the crystallization process in the glass melt. In a nutshell, the preparation of foam glass-ceramic as the porous structure derived from waste materials would give benefit to the economy and environment issue. It is a useful material to the various application in the industry depending on the type of porous structure.

Author Contributions: Conceptualization, D.I.S., M.H.M.Z.; formal analysis, D.I.S., M.H.M.Z.; resources, D.I.S.; writing—original draft preparation, D.I.S., M.H.M.Z.; writing—review and editing, D.I.S., M.H.M.Z., S.H.A.A., K.A.M.; supervision, M.H.M.Z., S.H.A.A., K.A.M. All authors have read and agreed to the published version of the manuscript.

Funding: Highest appreciation to Universiti Putra Malaysia (UPM) and Ministry of Higher Education Malaysia for financial support via Fundamental Research Grant Scheme (FRGS) Vote 5540276 for this research work. 
Conflicts of Interest: The authors declare no conflicts of interest.

\section{References}

1. Benzerga, R.; Laur, V.; Lebullenger, R.; Gendre, L.L.; Genty, S.; Sharaiha, A.; Queffelec, P. Waste-glass recycling: A step toward microwave applications. Mater. Res. Bull. 2015, 67, 261-265. [CrossRef]

2. Zaid, M.H.M.; Matori, K.A.; Ab Aziz,S.H.; Kamari, H.M.; Wahab, Z.A.; Effendy, N.; Alibe, I.M. Comprehensive study on compositional dependence of optical band gap in zinc soda lime silica glass system for optoelectronic applications. J. Non-Cryst. Solids 2016, 449, 107-112. [CrossRef]

3. Da Costa, F.P.; Morais, C.R.; Rodrigues, A.M. Sustainable glass-ceramic foams manufactured from waste glass bottles and bentonite. Ceram. Int. 2020, 46, 17957-17961.

4. Chen, Z.; Wang, H.; Ji, R.; Cheeseman, C.; Wang, X. Reuse of mineral wool waste and recycled glass in ceramic foams. Ceram. Int. 2019, 45, 15057-15064. [CrossRef]

5. König, J.; Petersen, R.R.; Yue, Y. Fabrication of highly insulating foam glass made from CRT panel glass. Ceram. Int. 2015, 41, 9793-9800. [CrossRef]

6. Sasmal, N.; Garai, M.; Karmakar, B. Preparation and characterization of novel foamed porous glass-ceramics. Mater. Charact. 2015, 103, 90-100. [CrossRef]

7. Zheng, W.M.; Sun, H.J.; Peng, T.J.; Zeng, L. Novel Preparation of Foamed Glass-ceramics from Asbestos Tailings and Waste Glass by Self-expansion in High Temperature. J. Non-Cryst. Solids 2020, 529, 119767. [CrossRef]

8. Fernandes, H.R.; Andreola, F.; Barbieri, L.; Lancellotti, I.; Pascual, M.J.; Ferreira, J.M.F. The use of egg shells to produce Cathode Ray Tube (CRT) glass foams. Ceram. Int. 2013, 39, 9071-9078. [CrossRef]

9. Xi, C.; Zheng, F.; Xu, J.; Yang, W.; Peng, Y.; Li, Y.; Li, P.; Zhen, Q.; Bahir, S.; Liu, J.L. Preparation of glass-ceramic foams using extracted titanium tailing and glass waste as raw materials. Constr. Build. Mater. 2018, 190, 896-909. [CrossRef]

10. Zaid, M.H.M.; Matori, K.A.; Wah, L.C.; Sidek, H.A.A.; Halimah, M.K.; Wahab, Z.A.; Azmi, B.Z. Elastic moduli prediction and correlation in soda lime silicate glasses containing ZnO. Int. J. Phys. Sci. 2011, 6, 1404-1410.

11. Zaid, M.H.M.; Matori, K.A.; Aziz, S.A.; Zakaria, A.; Ghazali, M.S.M. Effect of ZnO on the physical properties and optical band gap of soda lime silicate glass. Int. J. Mol. Sci. 2012, 13, 7550-7558. [CrossRef] [PubMed]

12. Doh, S.I.; Chin, S.C. Eggshell powder: Potential Filler in Concrete. In Proceedings of the Malaysian Technical Universities Conference of Engineering and Technology, Melaka, Malaysia, 10 November 2014; pp. 1-6.

13. Fernandes, H.R.; Ferreira, D.D.; Andreola, F.; Lancellotti, I.; Barbieri, L.; Ferreira, J.M.F. Environment friendly management of CRT glass by foaming with waste egg shells, calcite or dolomite. Ceram. Int. 2014, 40, 13371-13379. [CrossRef]

14. Fernandes, H.R.; Tulyaganov, D.U.; Ferreira, J.M.F. Preparation and characterization of foams from sheet glass and fly ash using carbonates as foaming agents. Ceram. Int. 2009, 35, 229-235. [CrossRef]

15. Vancea, C.; Lazău, I. Glass foam from window panes and bottle glass wastes. J. Chem. 2013, 12, $804-811$. [CrossRef]

16. Callister, W.D.; Rethwisch, D.G. Material Science and Engineering; University of Florida: Gainesville, FL, USA; Wiley: Hoboken, NJ, USA, 2013.

17. Liang, H.; Yang, Y.; Xie, D.; Li, L.; Mao, N.; Wang, C. Trabecular-like Ti-6Al-4V scaffolds for orthopedic: Fabrication by selective laser melting and in vitro biocompatibility. J. Mater. Res. Technol. 2019, 35, $1284-1297$. [CrossRef]

18. Liu, J.; Zhang, J.; Wu, J.; Liu, C.; Li, T.; Ning, Z.; Luo, X.; Zhou, X.; Yang, Q.; Lu, A. The utilization of electrical insulators waste and red mud for fabrication of partially vitrified ceramic materials with high porosity and high strength. J. Clean. Prod. 2019, 223, 790-800. [CrossRef]

19. Ji, R.; Zheng, Y.; Zou, Z.; Chen, Z.; Wei, S.; Jin, X.; Zhang, M. Utilization of mineral wool waste and waste glass for synthesis of foam glass at low temperature. Constr. Build. Mater. 2019, 215, 623-632. [CrossRef]

20. Arcaro, S.; Maia, B.G.; Souza, M.T.; Cecsoneto, F.R.; Granados, L.; Novaes de Oliveira, A.P. Thermal insulating foams produced from glass waste and banana leaves. Mater. Res. 2016, 19, 1064-1069. [CrossRef]

21. Wang, H.; Feng, K.; Sun, Q. Effect of calcium carbonate on the preparation of glass ceramic foams from water-quenched titanium-bearing blast furnace slag and waste glass. Adv. Appl. Ceram. 2018, 117, 312-318. [CrossRef] 
22. Ma, Q.; Wang, Q.; Luo, L.; Fan, C. Preparation of high strength and low-cost glass ceramic foams with extremely high coal fly ash content. In Materials Science and Engineering; IOP Publishing Ltd.: Shanghai, China, 2018; pp. 1-7.

23. Saparuddin, D.I.; Hisham, N.A.N.; Aziz, S.A.; Matori, K.A.; Honda, S.; Iwamoto, Y.; Zaid, M.H.M. Effect of sintering temperature on the crystal growth, microstructure and mechanical strength of foam glass-ceramics from waste materials. J. Mater. Res. Technol. 2020, 9, 5640-5647. [CrossRef]

24. Yao, S.Y.; Wang, P.; Shao, D.; Cao, H.X.; Zhang, W.W. Effect of ZnO on preparation and properties of $\mathrm{CaSiO}_{3}$ glass ceramics. Mater. Res. Innov. 2014, 18, 661-664. [CrossRef]

25. Petersen, R.R.; König, J.; Yue, Y. The viscosity window of the silicate glass foam production. J. Non-Cryst. Solids 2017, 456, 49-54. [CrossRef]

26. Bruckman, V.J.; Wriessnig, K. Improved soil carbonate determination by FT-IR and X-ray analysis. Environ. Chem. Lett. 2013, 11, 65-70. [CrossRef] [PubMed]

(C) 2020 by the authors. Licensee MDPI, Basel, Switzerland. This article is an open access article distributed under the terms and conditions of the Creative Commons Attribution (CC BY) license (http://creativecommons.org/licenses/by/4.0/). 